\title{
VN PHRASAL COMPOUNDS IN CINYANJA
}

\author{
Naomi Njobvu \\ University of Kwazulu-Natal \\ nananjobvu74@gmail.com
}

\begin{abstract}
This article aims at discussing verb-noun compounds with a locative prefix in the nominal part of the compounds in Cinyanja. The singular and plural forms of the compounds have been presented to show that the complex forms are nouns. With regard to the internal structure, the compounds show that they have a phrasal structure. Since verb-noun compounds in this study resemble the structure of synthetic compounds in English, the analysis of these words followed the syntactic approach. The results show that internally, the compounds with a locative have a verb phrase internal structure, and follow the verb-argument word order. In the syntactic context, it is shown that the compounds with the phrasal internal structure function as determiner phrases because they can appear in the subject and object positions in simple sentences and relative clauses. Further, the entire compound word can be modified by adjectives, and be coordinated with simple nouns, which suggests that the compounds with a locative are indeed determiner phrases. Finally, with the application of the lexical integrity hypothesis, the results reveal that the compounds with the locative in the nominal part are genuine compounds because they adhere to the lexical integrity principle.
\end{abstract}

Keywords: Cinyanja, V-N Compound, Lexical Integrity Hypothesis, Locatives, Verb Phrase

\section{Introduction}

This article analyses a category of compound words in Cinyanja, a Bantu language spoken mainly in the Eastern part of Zambia. These compound words are made up of a verb and a noun, which are grammatically and semantically related as shown below;

1. a. m-khala-pa-m-pando

1-sit-16.LOC-3-chair

'one who sits on the chair' (literal meaning)

'chairperson'

(lexical meaning)

b. ci-ponda-mu-thengo

7-step-18.LOC-5.bush

'it steps in the bush' (literal meaning)

'consultation fee' (lexical meaning)

In the examples above, the compound words consist of more than two words. In (1a) above, the compound word comprises the verb khala 'sit', the locative pa 'on' and the 
noun mpando 'chair' while in $1 \mathrm{~b}$ the compound comprises the verb ponda 'step', the locative $m u$ 'in' and the noun thengo 'bush'. The verb-noun (henceforth, $\mathrm{VN}$ ) compounds as shown in 1 above, have a complex structure because of the inflectional morphology that is part of these compounds.

Verb Norn compounds discussed in this article are particularly interesting because they resemble the structure of synthetic compound words in English of the truck-driver structure, which are based on deverbal heads. In the synthetic compound words in English, the non-head is typically an internal argument of the verb (Roeper and Siegel, 1978; Selkirk, 1982; Harley, 2009; Lieber, 2009a). Sometimes, synthetic compounds are called verbal compounds (Fabb, 1998; Olsen, 2001; Iordachioaia et al., 2017) because of the verbal element. For example, maker in shoemaker and driver in truck-driver. The nouns shoe and truck are considered internal arguments of the verb.

The main aim of this article is to contribute to the study of Bantu languages particularly Cinyanja (N31a), a Bantu language spoken in the Eastern part of Zambia. This is by providing an analysis of the morphology and syntax of $\mathrm{VN}$ compound words that have a locative in the nominal part. The main argument developed in this article is that although VN compound words with a locative in the nominal part have a phrasal internal structure of a verb phrase (VP) in Cinyanja, they are compounds. By using Bresnan and Mchombo's (1995) lexical integrity principles, this article demonstrates that the complex words with a VP internal structure are genuine nominal compounds.

The article is organised as follows; in Section 2, presents the theoretical framework which is followed by data collection method in Section 3. In section 4, the definition of compounding and compound words is given and this is followed by the morphological structure of $\mathrm{VN}$ compound words in section 5. The internal structure of the VN compound words is shown in Section 6. Section 7 discusses the VN compounds from the syntactic context and demonstrate that they function as noun phrases. In section 8 , the lexical integrity principle is applied on the complex structures, which have a locative in the nominal part to show that the complex words with the phrasal internal structure, are genuine nominal compounds.

\section{Theoretical Framework}

The analysis is based on the approach of synthetic compounds. In this theory, there are two approaches to the formation of synthetic compounds. One of the approaches postulates that synthetic compounds are formed when the base of the noun [N] combines with the nominalised verb [V-er]. This analysis of the compounds favours the lexicalists' approach (Bresnan and Mchombo, 1995; Scalise et al., 2009; Lieber, 2009a). It will not follow this approach because the analysis of $\mathrm{VN}$ compounds in this article is based on the syntactic approach.

The syntactic approach postulates that compounds are built on the basis of a combination of the verb and its argument noun $[\mathrm{N}+\mathrm{V}]$ to which the affix $-e r$ is attached (Fabb, 1984; Ackerman and Neeleman, 2001: 11; Booij, 2009: 219). In the case of a compound word such as truck-driver, the noun truck first merges with the verb drive to form a complex verb truck-drive to which the nominalising suffix is later added as shown in the structure below. 
3. a. truck-driver

b.

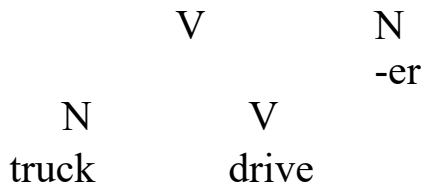

In $3 b$ above, the nominalising affix $-e r$ is suffixed to the entire compound not only to one of the compound constituents. This approach has been adopted because the complex verb provides the content under which the semantic interpretation of the compound as a whole is based. This is demonstrated in Section 6, where the internal structure of VN compounds in Cinyanja are shown. Before the internal structure is shown, the data collection methods are explained.

\section{Methods of Data Collection}

The main sources of data for this article were written texts such as Chichewa dictionaries, linguistics texts and reviewed articles. The researcher's knowledge of the language also supplemented the written texts. A list of compound words with locative markers inside them was compiled (such as cigonamubawa 'drunk'). The selection and categorisation was based on the general definition of a compound word as a combination of two or more words (see Plag, 2003:5), where the term 'word' is used to refer to meaningful unanalysable linguistic units (Di Sciullo and Williams, 1987; Lieber, 2009a). Therefore, names of people (kinship terms) and names of objects that met this definition were also considered as compounds.

\section{Compounding and Compound Words}

Compounding is one of the branches of morphology which deals with word-formation. Some scholars consider compounding the most productive process of word formation in most languages (Plag, 2003; Booij, 2009; Kiefer, 2009; Altakhaineh, 2016b). According to Ralli (2010: 57 ), the process of compounding involves combining words or stems to form a new complex item. Fiorentino (2006: 15) defines compounding as a process of word-formation that involves the joining of two or more open class morphemes to form larger complex words. For example, the combination of tea + pot forms the word teapot, and apple + juice + tray forms apple-juicy tray. Therefore, the combined words, teapot and apple-juice tray are called compound words.

Altakhaineh (2016a: 40) defines a compound word as a 'complex word that consists of at least, two adjacent elements, where the non-head is normally non-referential; and each of these elements is either a word, combining form or a phrase, so that the whole compound is a combination of these elements.' This definition seems to cover most of the important features that describe Cinyanja compound words in this paper. The only feature that does not fit the description of Cinyanja compound words is the term combining forms, which relates to compound words formed from roots of Greek and Latin origin (e.g. photoelectric), and will not be discussed further than this, in this article. 
However, one of the key features included in Altakhaineh's definition of a compound word is the non-restrictive position of phrasal elements, which seems to characterise most Cinyanja compounds. Other interesting features that emerge from Altakhaineh's definition of compound words, which are critical to the understanding and eventually, analysis of VN compound words with a locative in Cinyanja are: Adjacency, which Altakhaineh (2016b) defines as the impossibility of inserting a word between two words in a compound word. He notes that while it is possible to insert a word inside a phrase, for example a black ugly bird, it is not possible with a compound word blackbird. In compound words, ugly can only modify the entire compound word, for example, an ugly blackbird. Another feature is non-referentiality, which is used to mean that the non-head of the compound does not refer to any specific thing or item because it is generic in nature. These features describe Cinyanja VN compound words in this study which are presented in the next section.

\section{Structure of VN Compound Words}

In this section, the morphological structure of $\mathrm{VN}$ compounds in Cinyanja is considered. These compounds are particularly interesting because they resemble synthetic compound words in English (e.g. truck-driver). As indicated earlier, the VN compounds being analysed comprise a verb and a locative in the nominal part. Thus, these VN compounds can be schematically summarised as below;

$\mathrm{CM}+\mathrm{V}+\mathrm{FV}+\mathrm{LOC}+(\mathrm{CM}) \mathrm{N}$

Examples of this type of VN compound words are presented in Table 1, which shows the singular and plural forms of $\mathrm{VN}$ compounds with a locative inside them.

Table 1: Singular and Plural Forms of VN Compounds with a Locative

\begin{tabular}{|c|c|c|}
\hline No: & Singular Forms of Compounds & Plural Forms of Compounds \\
\hline a. & $\begin{array}{l}\text { ci-pond-a-mu-thengo } \\
\text { 7-step-FV-18.LOC-5.bush } \\
\text { 'consultation fee' }\end{array}$ & $\begin{array}{l}\text { ci-pond-a-mu-thengo } \\
\text { 8-step-FV-18.LOC-5.bush } \\
\text { 'consultation fees' }\end{array}$ \\
\hline$b$ & $\begin{array}{l}\text { ci-gon-a-mu-bawa } \\
\text { 7-sleep-FV-18.LOC-5.bar } \\
\text { 'a drunk' }\end{array}$ & $\begin{array}{l}\text { a-ci-gon-a-mu-bawa } \\
\text { 2-7-sleep-FV-18.LOC-5.bar } \\
\text { 'drunks' }\end{array}$ \\
\hline $\mathrm{c}$ & $\begin{array}{l}\text { m-khal-a-pa-mw-ala } \\
\text { 1-sit-FV-16.LOC-3-stone } \\
\text { 'stone sitter' }\end{array}$ & $\begin{array}{l}\text { a-m-khal-a-pa-mw-ala } \\
\text { 2-1-sit-FV-16.LOC-3-stone } \\
\text { 'stone sitters' }\end{array}$ \\
\hline $\mathrm{d}$ & $\begin{array}{l}\text { m-khal-a-pa-citsa } \\
\text { 1-sit-FV-16.LOC-stump } \\
\text { 'stump sitter/idle person' }\end{array}$ & $\begin{array}{l}\text { a-m-khal-a-pa-citsa } \\
\text { 2-1-sit-FV-16.LOC-stump } \\
\text { 'stump sitters' }\end{array}$ \\
\hline $\mathrm{e}$ & $\begin{array}{l}\text { m-ses-s-a-pa-khomo } \\
\text { 1-sweep-FV-16.LOC-5.yard } \\
\text { 'maid' }\end{array}$ & $\begin{array}{l}\text { a-m-ses-a-pa-khomo } \\
\text { 2-1-sweep-FV-16.LOC-5.yard } \\
\text { 'maids' }\end{array}$ \\
\hline
\end{tabular}

The compounds in this category refer to humans, objects and things. The majority of the compounds have class 16 or class 18 locatives. It is observed that compounds with 
the initial prefix $m$ - and refer to humans, have the class 2 plural prefix $-a$ added to the compound word as a whole. Crucially, the compounds with the class 7 prefix $c i$ - that refer to humans such as cigonamubawal 'drunk' also take class 2 plural prefix $-a$, not their regular class 8 plural prefix $z i$ - in Cinyanja. However, compound words with the initial prefix $c i$ - such as cipondamuthengo 'consultation fee' that refer to mass nouns rather than to humans, do not take class 8 plural prefix $z i$ - either. The fact that these compounds can be pluralised, and that other compounds have characteristics of mass nouns, shows that they are nouns.

In the compound words above, noun class prefixes and locative prefixes are prominent features in the compound words, and Carstens (2008) analyses them as inflectional elements.

\section{Phrasal Structure of VN Compounds}

In this section, it is shown that internally, $\mathrm{VN}$ compounds have a phrasal structure because the locative prefixes inside the compounds are inflectional. Following Abeny (1987) and much later works, Carstens (1993) analyses Bantu noun phrases as determiner phrases (DPs). In the analysis of the internal structure of Cinyanja VN compounds, the representation of 'ordinary' and locative noun phrases as DPs and locative determiner phrase $\left(\mathrm{DP}_{\mathrm{LOC}}\right)$ respectively are adopted. It is argued that the $\mathrm{VN}$ complex expressions are based on a syntactic combination of $\mathrm{V}+\mathrm{DP}$ (with ' $\mathrm{V}$ ' standing for a root), which is a VP (Di Sciullo and William, 1987; Lieber, 1992; Mchombo, 2004). These VPs are eventually nominalised by the first noun class prefix to form VN compounds. In this case, the nominaliser attaches to the VP to form the nominal compound as shown in Table 2 below.

Table 2: Phrasal Structure of VN Compounds.

\begin{tabular}{|c|c|c|c|}
\hline $\mathbf{S} / \mathbf{N}$ & Compound & Verb Phrase & Translation \\
\hline a. & $\begin{array}{l}\text { ci-gona-mu-bawa } \\
\text { 7-sleep-18.LOC-5.bawa } \\
\text { drunk }\end{array}$ & $\begin{array}{l}\text { gona mu bawa } \\
\text { V LOC DP }\end{array}$ & sleep in the bar \\
\hline b. & $\begin{array}{l}\text { ci-ponda-mu-thengo } \\
\text { 7-step-18.LOC-5.bush } \\
\text { consultation fee }\end{array}$ & $\begin{array}{l}\text { ponda mu thengo } \\
\mathrm{V} \text { LOC DP }\end{array}$ & step in the bush \\
\hline c. & $\begin{array}{l}\text { m-khala-pa-mwala } \\
\text { 1-sit-16.LOC-3-stone } \\
\text { stone sitter }\end{array}$ & $\begin{array}{l}\text { khala pa mwala } \\
\mathrm{V} \text { LOC DP }\end{array}$ & sit on the stone \\
\hline d. & $\begin{array}{l}\text { m-sesa-pa-khomo } \\
\text { 1-sweep-16.LOC-yard } \\
\text { maid }\end{array}$ & $\begin{array}{l}\text { sesa pa khomo } \\
\mathrm{V} \text { LOC DP }\end{array}$ & sweep the yard \\
\hline e. & $\begin{array}{l}\text { m-khala-pa-citsa } \\
\text { 1-sit-16.LOC-stump } \\
\text { Stump sitter (idle person) }\end{array}$ & $\begin{array}{l}\text { khala pa citsa } \\
\mathrm{V} \quad \text { LOC DP }\end{array}$ & sit on the stump \\
\hline
\end{tabular}

1 In other languages such as Chichewa of Malawi, it is likely that the compound word cigonamubawa 'drunk' may take the regular plural marker -zi of noun class 8, thus zigonamubawa. However, in Zambia, Cigonamubawa optionally takes the plural in class 2 as a-cigonamubawa 'drunks'. 
Internally, VN compounds in Table 2 above have a VP word order. According to Miti (2001), VPs in most Bantu languages, normally comprise an obligatory verb, which may be followed by a noun phrase, a locative or an adverbial phrase. Therefore, it is claimed in this article that the Cinyanja VN compounds above are based on the phrasal structure of a $\mathrm{V}+\mathrm{DP}_{\mathrm{LOC}}$, that is, they have a complete VP structure inside them. Evidence of this view is that the verb locative or adverbial phrase word order is preserved in these compound words as shown in Table 2. Despite the VP internal structure, these compounds behave just like nouns/DPs as discussed below.

\section{VN Compound Words as DPs}

In this section, I discuss VN compounds with a locative in the nominal position in the syntactic context and show that they appear in the same syntactic context as DPs. VN compounds with a locative can appear in the subject and object positions in simple sentences, and in relative clauses. The entire compound word can also be modified by an adjective, and can be coordinated with simple nouns suggesting that they are indeed nouns.

In a basic clause structure, VN compounds can function as subject of a verb in a sentence. Consequently, they agree in the class indicated by the first prefix as shown in the examples.

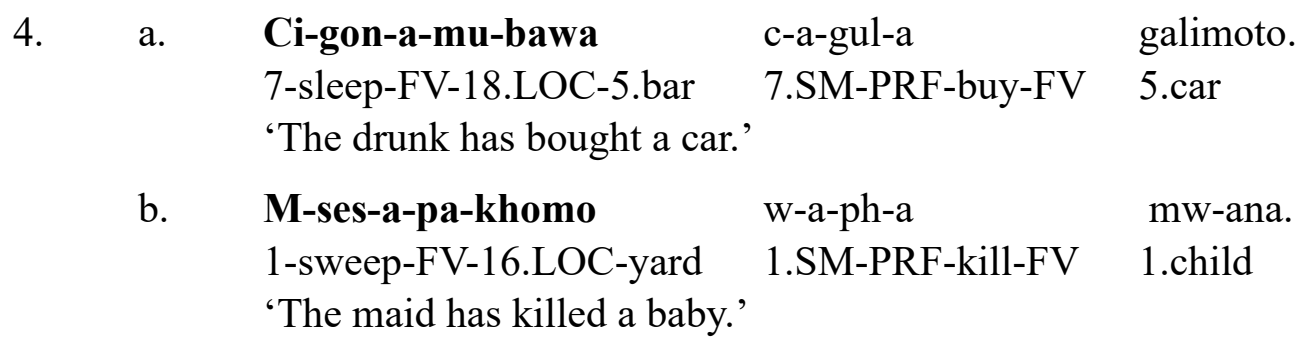

In $4 \mathrm{a}$ above, the subject is cigonamubawa and the initial prefix $c i$ - of noun class (NC) 7 is reflected on the verb as a subject agreement marker. In 4b, Msesapakhomo is the subject of the clause, and its initial class $1 \mathrm{NC}$ prefix $m$ - is indicated in the verb as a subject marker. Noteworthy, is that, $\mathrm{VN}$ compounds in class 7 that refer to humans can also trigger agreement in class 1 as shown below.

5

$$
\begin{array}{lll}
\text { Ci-gon-a-mu-bawa } & \text { w-a-gul-a } & \text { galimoto. } \\
\text { 7-sleep-FV-18.LOC-5.bar } & \text { 1-PRF-buy-FV } & \text { 5.car }
\end{array}
$$

'The drunk has bought a car.'

Another indication that VN compounds are DPs is that they can function as nominal objects as shown in 6a and b; cipondamthengo and mkhalapamwala.
6.
a.
M-phunzitsi
w-a-lipir-a
ci-pond-a-m-thengo.
1-teacher
1.SM-PRF-paid-FV
7-step-FV-18.LOC-5bush
'The teacher has paid consultation fees.'
b. A-nyamata a-na-pirikits-a
2.SM-PST-chase-FV
m-khal-a-pa-mw-ala.
2-boy
1-sit-FV-16.LOC-3-stone
'Boys chased the stone sitter.'


Another observation about word order is that when the object marker (OM) is part of the verbal morphology, the entire compound word can be left dislocated as in $7 \mathrm{~b}$ or right dislocated as in $7 \mathrm{c}$.

7. a. M-tsikana w-a-ci pand-a Ci-gon-a-mu-bawa

1-girl 1-PRF-OM-beat-FV 7-sleep-FV-18.LOC-5.bar

ca u-lesi.

7.ASS 14-lazy

'The girl has beaten the lazy drunk.'

b. Ci-gon-a-mu-bawa, m-tsikana w-a-ci-pand-a

7-sleep-FV-18.LOC-5.bar 1-girl 1-PRF-7.OM-beat-FV ca

u-lesi

7.ASS 14-lazy

'The drunk, the girl has beaten him, the lazy one.'

c. $\mathrm{Ca}$ u-lesi, w-a-ci-pand-a m-tsikana,

7.ASS 14-lazy 1-PRF-7.OM-beat-FV 1-girl

ci-gon-a-mu-bawa

7-sleep-FV-18.LOC-5.bar

'The lazy one, the girl has beaten him, the drunk.'

However, when the OM is absent on the verb, left and right dislocation of the compound words is impossible as shown below.

8.

a.

*Ci-gon-a-mu-bawa

7-sleep-FV-18.LOC-5.bar 1-girl 1-PRF-beat-FV

ca

u-lesi

7.ASS

14.lazy

*'The drunk, the girl has beaten the lazy one.'

b. $\quad * \mathrm{Ca} \quad$ u-lesi

7.AA 14-lazy

w-a-pand-a

m-tsikana,

\section{ci-gon-a-mu-bawa.}

1-PRF-beat-FV 1-girl

7-sleep-FV-18.LOC-5.bar

*'The lazy one, has beaten the girl the drunk.'

Further, VN compounds like nouns can also head a relative clause as nominal subjects or they can be used as objects. For better clarity, cigonamubawa in 9a is an object of the clause and is used as a base example from which $9 b$ and $9 c$ are drawn. In $9 b$, the $\mathrm{VN}$ compound cigonamubawa 'drunk' is the subject of the relative clause while in 9c cigonamubawa is the object of the relative clause.

9.

a. Mw-ana

a-na-on-a

ci-gon-a-mu-bawa

1-child

1.SM-PST-see-FV

7-sleep-FV-18.LOC-bar

m-nyumba.

18.LOC-house

'The child saw the drunk in the house.' 
b.

$\begin{array}{lll}\text { Ci-gon-a-m-bawa } & \text { ci-mene } & \text { ci-na-wonedw-a } \\ \text { 7-sleep-FV-18.LOC-5.bar } & \text { 7-REL } & \text { 7.SM-PST-see-PASS-FV ndi }\end{array}$

mw-ana

$\mathrm{mu}$

nyumba, ci-na-kwatir-a

by 1-child

18.LOC 9. house

7-PST-marry-FV

ci-ph-adzuwa.

7- kill-FV- sun

'The drunk who was seen by the child in the house, married a beautiful girl.'

c.

$\begin{array}{llcc}\text { Ci-gon-a-mu-bawa } & \text { ci-mene } & \text { mw-ana } & \\ \text { 7-sleep -FV-18.LOC-5.bar } & \text { 7.SM-REL } \quad 1 \text {-child } & \\ \text { a-na-on-a } & \text { m'nyumba, ci-na-kwatir-a } & \text { ci-ph-a-dzuwa } \\ \text { 1.SM-PST-see-FV } & \text { 18.LOC-house 7-PST-marry-FV } & \text { 7-kill-FV-sun } \\ \text { 'The drunk whom the child saw in the house, married a beautiful girl.' }\end{array}$

Another characteristic behaviour of the VN compounds with a locative as DPs is that they can be coordinated with simple nouns. This is shown in the example below.

10 .
a.
Ci-gon-a-mu-bawa
ndi galu w-ake a-a-pit-a
7-sleep-FV-18.LOC-5
and 1.dog 1-his
ku-dambo.
17.LOC-5. swamp
'The drunk and his dog have gone to the swamp.'
b.

\begin{tabular}{|c|c|c|}
\hline M-ses-a-pa-kh & kapena & M-sangalatsi \\
\hline 1-sweep-FV-16 & 5. yard or & 1-entertainer \\
\hline w-a-gul-a & m-thuthuthu & \\
\hline 1-PRF-buy-F & 3-motorbike & \\
\hline
\end{tabular}

2.PRF-go-FV

From the examples in 10 above, it is clear that compound words like nouns can conjoin with other simple nouns. When a class 7 compound conjoins with class 1 noun as in 10a, the verb agrees in the plural of class 2 . However, when two class 1 nouns are coordinated by kapena 'or' as in 10b the verb agrees in class 1 . This is because kapena has a semantic interpretation of alternative, thus, the first noun triggers agreement on the verb. Another indication that $\mathrm{VN}$ compounds are nouns is that they can be modified.

VN compounds, like nouns, can also be modified by adjectives. In this case, modification affects the entire compound word not only the nominal constituent inside the compound as illustrated below.
11.
a.
Ci-gon-a-mu-bawa
ca-nzeru
ca-gul-a
nyumba.
7-sleep-FV-18.LOC-5.bar
7.ASS-wise
7.PRF-buy-FV 9.house
'A wise drunk has bought a house.'
b. *Ci-gon-a-m-bawa
ya-nzeru
ca-gul-a
7-sleep-FV-18.LOC-5.bar
5.ASS-wise
7.ASS-buy-FV
nyumba.

9.house 
From the examples above, it is clear that VN phrasal compounds function as nouns. However, to confirm that VN phrasal compounds with the VP internal structure are not VPs, the lexical integrity test is applied as discussed in Section 8 below.

\section{VN Compounds and the Lexical Integrity Hypothesis}

The lexical integrity hypothesis (LIH) suggests that syntax cannot manipulate or have access to the internal structure of words (Lapointe, 1980; Di Sciullo and Williams, 1987; Anderson, 1992; Bresnan and Mchombo, 1995; Ackema and Neeleman, 2003; Booij, 2009; Lieber, 2009a). The main argument behind this principle is that morphological and syntactic rules are different. As a result, pieces of words cannot be manipulated by syntactic operations and cannot be accessible to elements outside of the word.

In this section, I use some tests to show that VN phrasal compounds with a VP internal structure are indeed compound words. The tests include; anaphoric pronominal replacement test (see also Lieber, 2009b; Lieber and Stekauer, 2009; Haspelmath and Sims, 2010), and extraction and gapping (Bresnan and Mchombo, 1995).

\section{Anaphoric Pronominal Replacement Test}

The anaphoric pronominal replacement test is used to show that a part of VN compounds with a VP internal structure cannot be replaced by a pronoun and/or deictic pronoun (see also Bresnan and Mchombo, 1995 test on inbound anaphoric island in Chichewa synthetic compounds). In syntactic phrases, it is possible to substitute the second word in the NP with a pro-form. For example, we can say a black one to refer to a black bird in a phrase. But in a compound word blackbird, it is impossible to replace bird with one; for example, *blackone. Further, in the examples below, the noun watch in the phrase gold watch, in 12a has been replaced with pro-form one, which means that gold watch is a phrase. In contrast, in example $12 \mathrm{~b}$ the head noun, smith, cannot be substituted by a pronominal item one, which shows that goldsmith is a compound. Examples $12 \mathrm{a}$ and $12 \mathrm{~b}$ are from Haspelmath and Sims (2010: 194).

12. a. My aunt has one gold watch and three silver ones.

b. *My aunt knows one goldsmith and three silverones.

Similarly, in Cinyanja, pronominal replacement is allowed in syntactic structures such as 13a and 13b. For example, the noun khomo, 'yard', in the VP sesa pa khomo, 'sweep the yard', can be replaced by iyo, 'that', as shown in example 13b. However, in 14b, anaphoric pronominal replacement of -khomo, 'yard' with iyo is impossible because msesapakhomo 'maid', is a compound word.

13. a. A-na-sesa pa khomo.

'She swept the yard'.

b. A-na-sesa iyo.

'She swept that one (i.e. yard)' 
a. M-ses-a-pa-khomo w-a-thaw-a.

1-sweep-FV-16.LOC-5-yard 1-PRF-run-FV

'The maid has run away.'

b. *M-ses-a-pa-iyo w-a-thaw-a.

1-sweep-FV16.LOC-that 1-PRF-run-FV

Intended: 'The maid has run away.'

The example in $14 \mathrm{~b}$ shows that a part of the compound word, (that is the noun constituent) cannot be substituted by a pronominal form. This provides evidence that these expressions are compound words.

\section{Extraction}

Another test, extraction, is used to show that constituents of a compound word can neither be relativised nor topicalised (Bresnan and Mchombo, 1995). For example, we cannot extract apple-juice from the compound word, apple-juice tray, or relativise it because the sentence will be unacceptable.

15. a. The boy bought the apple-juice tray yesterday.

b. *Apple juice, which the boy bought tray yesterday.

In Cinyanja, extraction of the noun from a VN compound is equally disallowed. Bresnan and Mchombo (1995) show that arguments of the verb can undergo extraction in Chichewa. However, despite the fact that the nominal part of VN compounds constitutes an argument of the verb, as shown in section 6 , the constituents that form these compounds cannot be relativised or topicalised. In example 16a the VN compound cigonamubawa 'drunk' is the internal object argument of the verb waona 'has seen'. In 16b, the whole expression has been relativised. However, relativisation of only the nominal part of the compound word renders the construction ungrammatical, as shown in $16 \mathrm{c}$.

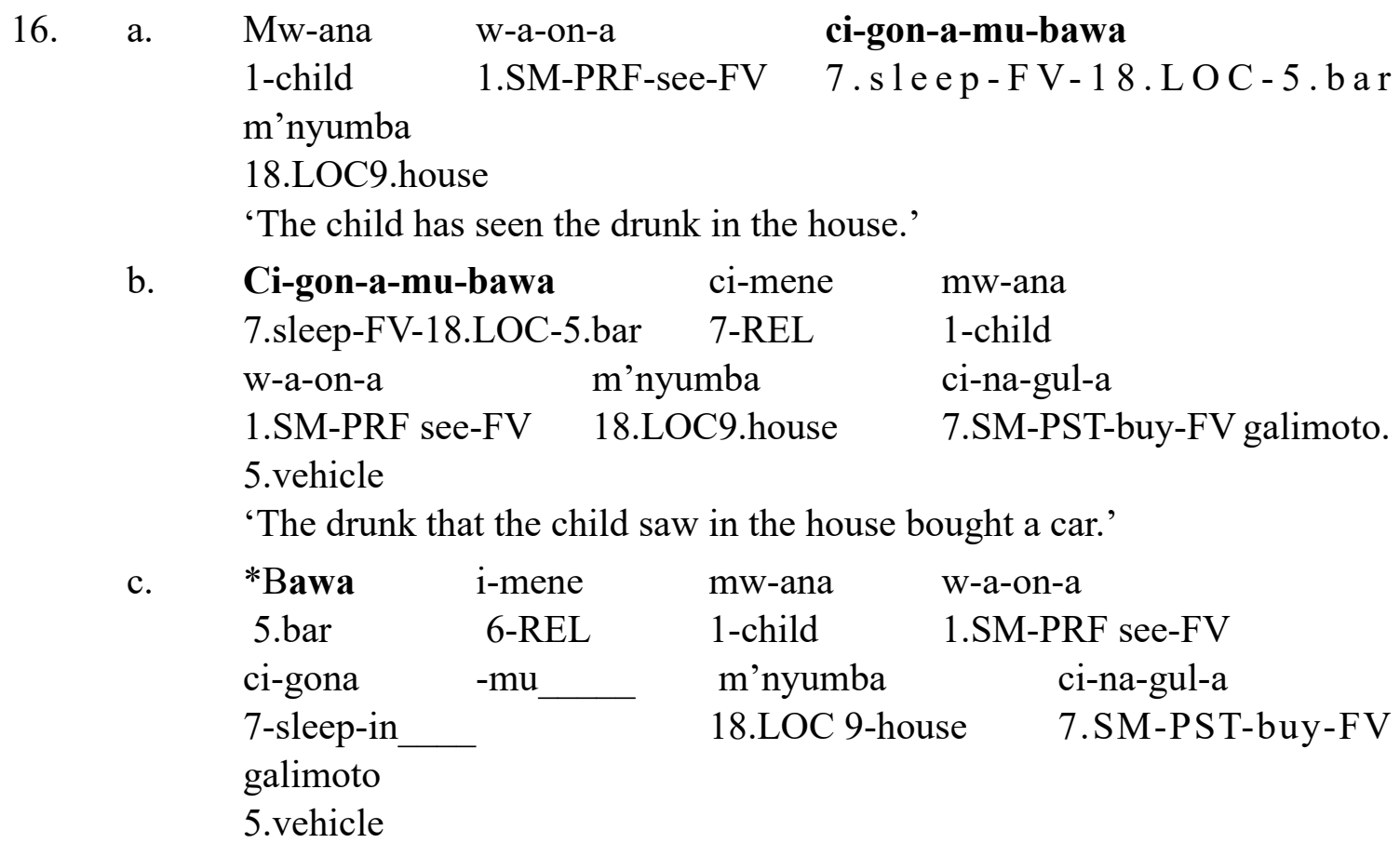


The example in 16c shows that extraction of a noun from the $\mathrm{VN}$ complex expression is not allowed.

\section{Gapping}

Another test, gapping, is also based on Bresnan and Mchombo's (1995) argument that it is not possible to gap a part of a morphological word. In their analysis, Bresnan and Mchombo show that it is possible to gap the verb as in $17 \mathrm{~b}$ without affecting the grammaticality and semantic interpretation of a sentence because the verb is an independent syntactic constituent. However, in $18 \mathrm{~b}$, it is impossible to elide driver from the compound taxidriver because taxi-driver is a morphological word.

17. a. John sat on the table and Mary sat on the chair.

b. John sat on a table and Mary on the chair.

18. a. John is a bus-driver and Mary is a taxi-driver.

b. *John is a bus-driver and Mary is a taxi

As discussed by Bresnan and Mchombo (1995), they show that the noun inside the complement of a locative prefix can be gapped, which is one of the arguments that Bresnan and Mchombo provide to show that the locative is a syntactic construct. However, in a VN compound, when two locatives from the same noun class appear in two coordinated VN compounds, gapping of identical material is impossible. Example 19b demonstrates this for the locative prefix, and 19c shows that the noun inside the complement of the prefix cannot be gapped either:

19.

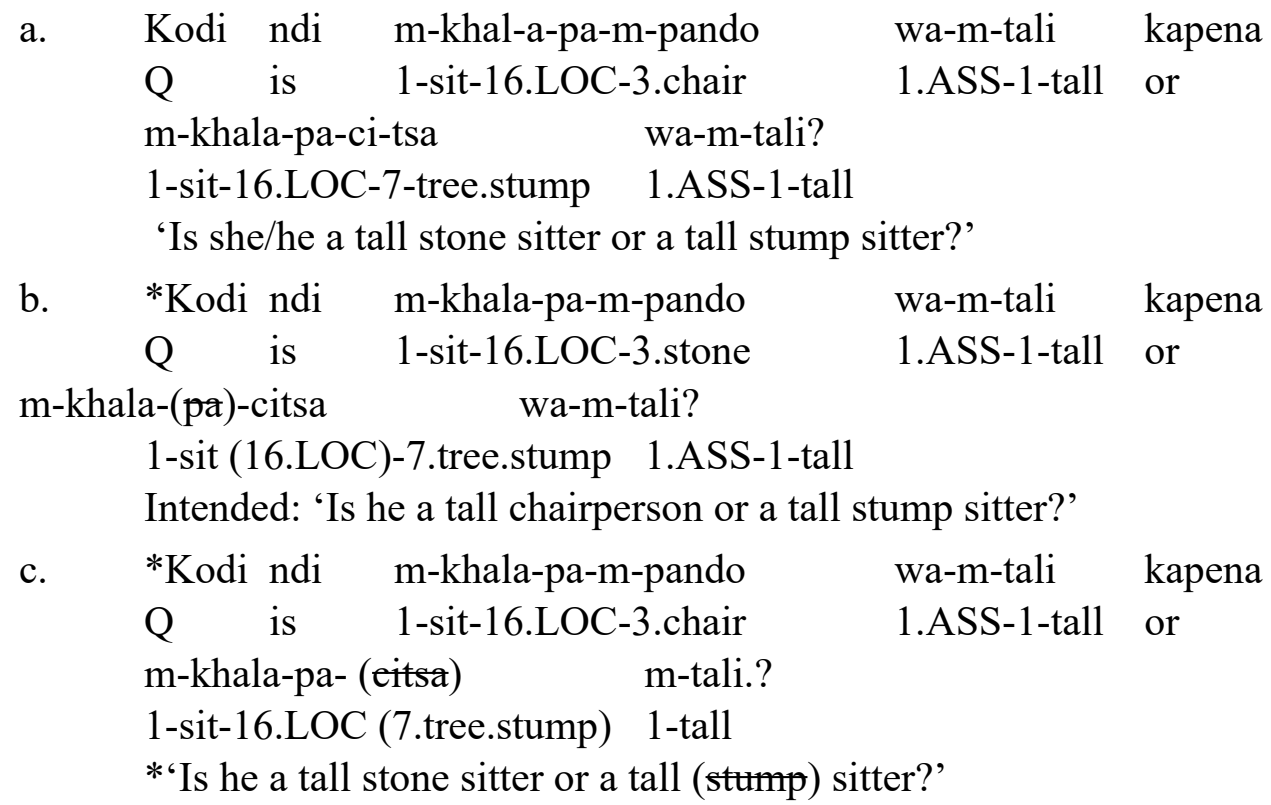

From the examples above, it is clear that eliding the locative prefix in $19 b$, or the complement DP of the locative in $19 \mathrm{c}$, renders these compounds unacceptable. This clearly demonstrates that the VN compounds with a locative are morphological words, and are indeed nominal compound words. 
In sum, the tests that have been applied above show that the phrasal structure in VN compounds is not accessible to syntactic operations and processes that can be applied to syntactically independent constituents.

\section{Conclusion}

This article shows that the VN compound words with a locative in the nominal part have a phrasal structure of a VP. It has been demonstrated that despite the VP internal structure, the VN compounds are nouns because they can be pluralised, and can function as subjects and objects of simple sentences and relative clauses. Further, evidence that the $\mathrm{VN}$ compounds with a $\mathrm{DP}_{\mathrm{LOC}}$ structure are indeed compound words is that they obeyed the lexical integrity principles such as pronominal replacement, extraction and gapping.

\section{References}

Abney, S.P. (1987). The English Noun Phrase in its Sentential Aspect. PhD Dissertation. Cambridge, MIT Mass.

Ackema, P., and Neeleman, A. (2001). Competition between Syntax and Morphology. In Legendre, G., Grimshaw, J., and Vikner, S. (eds). Optimality Theoretic Syntax. MIT Press, 29-60.

Ackema, P., and Neeleman, A.D. (2004). Beyond Morphology. Interface Conditions on Word Formation: Studies in Theoretical Linguistics.

Altakhaineh, A.R.M. (2016a). Compounding in Modern Standard Arabic, Jordanian Arabic and English. PhD Dissertation. New Castle University.

Altakhaineh,A.R.M.(2016b). What is a Compound? The Main Criteria for Compoundhood. ExELL (Explorations in English Language and Linguistics) 4 (1): 58-86.

Anderson, S.R. (1992). A-Morphous Morphology. Cambridge: Cambridge University Press.

Booij, G. (2009). Compounding and Construction Morphology, in Lieber, R., and Tekauer, P. (eds). The Oxford Handbook of Compounding. Oxford: Oxford University Press, 201-216.

Bresnan, J., and Mchombo, S. (1995). The Lexical Integrity Principle: Evidence from Bantu Languages. Natural Languages and Linguistic Theory. Springer, 13 (2): 181-254.

Carstens, V. (2008). DP in Bantu and Romance, in Demuth, K., and De Cat, C. (eds.). The Bantu-Romance Connection. Amsterdam: John Benjamins, 131-166.

Carstens, V. (1993). On Nominal Morphology and DP Structure, in Sam A. Mchombo (ed.), Theoretical Aspects of Bantu Grammar, 151-180. Stanford: CSLI.

Di Sciullo, A.M., and Williams, E. (1987). On the Definition of Word. Cambridge Mass: MIT Press.

Fabb, N. (1998). Compounding, in Spencer, A., and Zwicky, A.M. (eds.). The Handbook of Morphology. Oxford: Blackwell, 66-83. 
Fabb, N.A.J. (1984). Syntactic Affixation. PhD Dissertation. Massachusetts Institute of Technology, Boston.

Fiorentino, R.D. (2006). Lexical Structure and the Nature of Linguistic Representations. $\mathrm{PhD}$ Dissertation. University of Maryland, College Park.

Harley, H. (2009). Compounding in Distributed Morphology, in Lieber, R., and Štekauer, P. (eds.). The Oxford Handbook of Compounding. Oxford: Oxford University Press, 129-144.

Haspelmath, M., and Sims, A.D. (2010). Understanding Morphology. Oxford: Oxford University Press.

Iordachioaia, G., Alexiodou, A. and Pairamidis, A. (2017). Morphosyntactic Sources for Nominal Synthetic Compunds in English and Greek. Zeitschrift fur wortildung/journal of Word Formation, 1 (1), pp 47-72.

Kiefer, F. (2009). Uralic, Finno-Ugric: Hungarian, in Lieber, R., and Štekauer, P. (eds). The Oxford Handbook of Compounding. Oxford: Oxford University Press, 527-541.

Lieber, R., and Stekauer, P. (2009). Introduction: Status and Definition of Compounding. in Lieber, R. and Štekauer, P. (eds.). The Oxford Handbook of Compounding. Oxford: Oxford University Press.

Lieber, R. (2009a). Introducing Morphology. New York: Cambridge University Press.

Lieber, R. (2009b). A Lexical Semantic Approach to Compounding, in Lieber, R., and Stekauer, P. (eds). The Oxford Handbook of Compounding. Oxford: Oxford University Press, 78-104.

Lieber, R. (1992). Deconstructing Morphology: Word Formation in Syntactic Theory. Chicago, Illinois: University of Chicago Press.

Lapointe, S. (1980). A Theory of Grammatical Agreement. PhD. Dissertation. Amherst, University of Massachusetts.

Mchombo, S. (2004). The Syntax of Chichewa. Cambridge: Cambridge University Press.

Miti, L. (2001). A Linguistic Analysis of Cinsenga. A Bantu Language Spoken in Zambia and Malawi. Cape Town: The Centre for Advanced Studies of African Society(SAS).

Olsen, S. (2001). Copulative Compounds: A Closer Look at the Interface between Morphology and Syntax, in Yearbook of Morphology 2000. Dordrecht: Kluwer, 279320.

Plag, I. (2003). Word-Formation in English. Cambridge: Cambridge University Press.

Ralli, A. (2010). 'Compounding Versus Derivation,' in Scalise, S., and Vogel, I. (eds). Cross Disciplinary Issues in Compounding. Amsterdam: John Benjamins Publishing. 57-76.

Roeper, T., and Siegel, M.E.A. (1978). A Lexical Transformation for Verbal Compounds. Linguistic Inquiry, 9:199-260.

Scalise, S., Fabregas, A., and Forza, F. (2009). Exocentricity in Compounding. (Gengo Kenkyu), 135, 49-84.

Selkirk, E.O. (1982). The Syntax of Words. Cambridge, Mass: MIT Press. 